\title{
APLIKASI TEKNOLOGI PENGOLAHAN AIR SEDERHANA UNTUK MASYARAKAT PEDESAAN
}

\author{
Oleh : \\ Arie Herlambang dan Nusa Idaman Said \\ Kelompok Teknologi Pengelolaan Air Bersih dan Limbah Cair, Pusat Pengkajian dan Penerapan Teknologi \\ Lingkungan, BPPT
}

\begin{abstract}
The level of water services by PDAM (Local Water Service Company) is still 19,4\% of Indonesian population. Most of them still rely on groundwater, spring, river and rain. In the big and medium cities the level of water services higher between $40-50$ and 20 $30 \%$ respectively, but in rural still very low. Recently many source of water is contaminated by domestic, industry, and agricultur waste due to lack of attention of water users to environment. Beside, some dense populated areas with low sanitation fasility make many shalow well contaminated by E.coli. For improving rural water services, It needs government policy that encourage bigger role of rural comunity to develop their ability and organization that maintain and protect source, process, production and distribution of water. Information of Simple Water Treatment Technology is an important that must be distributed to people who live in village or remote areas, in order to improve their knowledge. BPPT has been along time to develop many kind of water treatment technologies for treating river water, groundwater, peatwater, calcareous water,poluted water, brachist water or even sea water to make clean water or potable water. Many of those technologies have already applied in many areas in Indonesia, and up to now BPPT still develop many kind of water treatment technologies for the future.
\end{abstract}

Kata Kunci : air bersih, pengolahan air, masyarakat pedesaan.

\section{PENDAHULUAN}

Air merupakan unsur utama kehidupan, kita mampu bertahan hidup tanpa makan dalam beberapa minggu, namun tanpa air kita akan mati dalam beberapa hari saja. Dalam bidang kehidupan ekonomi modern kita, air juga merupakan hal utama untuk budidaya pertanian, industri, pembangkit tenaga listrik, dan transportasi. Oleh karena itu seharusnya air diperlakukan sebagai bahan yang sangat bernilai, dimanfaatkan secara bijak, dan dijaga terhadap pencemaran. Namun kenyataannya tidak jarang air dihamburkan, dicemari, dan disia-siakan. Sebagai akibatnya hampir separo penduduk dunia, khususnya di negara-negara berkembang, menderita berbagai penyakit yang diakibatkan oleh kekurangan air, atau oleh air yang tercemar. Menurut Organisasi Kesehatan Dunia, dua miliar orang kini menyandang risiko menderita penyakit diare yang disebabkan oleh air dan makanan. Penyakit ini merupakan penyebab utama kematian lebih dari lima juta anak-anak setiap tahun.

Selain itu perkembangan penduduk yang pesat menimbulkan dampak meningkatnya kebutuhan air bersih, dan bersamaan dengan itu meningkat pula limbah yang dihasilkan. Sumbersumber air semakin dicemari oleh limbah industri yang tidak diolah atau tercemar karena penggunaannya yang melebihi kapasitasnya untuk dapat diperbaharui. Jika tidak ada perubahan radikal dalam cara memanfaatkan air, suatu ketika air tidak lagi dapat digunakan tanpa pengolahan khusus yang biayanya melebihi jangkauan sumber daya ekonomi bagi kebanyakan negara.

Sebagai contoh, jika dilihat perkembangan tingkat pelayanan air bersih untuk perkotaan dari tahun ke tahun tidak banyak peningkatan, hanya berkisar $40-50 \%$ untuk kota besar dan sekitar $20-30 \%$ untuk kota kecil. Dilain sisi tingkat pencemaran sumber-sumber air permukaan semakin meningkat, terutama dari sumber limbah domestik, industri dan pertanian. Padatnya pemukiman mengakibatkan pula sanitasi lingkungan tidak terkendali, sehingga banyak dijumpai sumur-sumur penduduk dikotakota yang tercemar oleh bakteri $E$. coli. Permasalahan air bersih dihadapi pula di lokasi transmigrasi, seperti di Air Rengit, Kabupaten Banyuasin, Sumatera Selatan yang airnya asam, sulitnya medan membuat sekitar 2.100 transmigran yang telah menempati kawasan itu sejak tahun 1996 terpaksa meninggalkan lokasi. $\mathrm{Di}$ daerah tersebut airnya berwarna merah kehitam-hitaman, sesuai dasar tanah gambut yang ada di kawasan itu. Kondisi ini juga di jumpai di lokasi transmigrasi lain di Kalimantan Tengah dan Selatan, seperti di Pangkoh dan 
Aluh-Aluh. Di samping Air gambut, di beberapa wilayah transmigrasi juga kekurangan sumber air tawar, akibat musim kemarau yang panjang, yang ada hanya air tanah yang payau atau asin. Keterbatasan kemampuan memaksa mereka harus berjalan jauh atau mengeluarkan uang lebih untuk mendapatkan air bersih.

Seperti telah disebutkan sebelumnya sebagian besar penduduk bumi berada di negara-negara berkembang. Jika ingin mendapatkan sumber air yang layak, dan menginginkan ekonomi yang berkembang dan berindustrialisasi, maka prilaku terhadap air harus dirubah, bagaimanapun masalah penyediaan air tidak dapat ditangani secara terpisah dari masalah lain. Buangan air yang tak layak dapat mencemari sumber air, dan sering kali tak teratasi. Ketidaksempurnaan dalam layanan umum, sistem saluran hujan yang kurang baik, sistem pembuangan limbah padat yang buruk juga dapat menyebabkan lingkungan hidup yang kurang sehat. Dengan demikian dalam jangka panjang akan sangat penting memikirkannya dari segi pengintegrasian layanan-layanan lingkungan ke dalam suatu paket pengelolaan air, sanitasi, saluran, dan limbah padat yang komprehensif.

Mengingat terbatasnya kemampuan pemerintah dalam pelayanan air bersih, maka diperlukan upaya pemberdayaan masyarakat dalam pengadaan air bersih melalui pemahaman teknologi pengolahan air sederhana yang mudah dimengerti dan dipraktekkan masyarakat. Upaya pemberdayaan ini perlu dilakukan dengan bantuan pemerintah melalui instansi terkait atau lembaga swadaya masyarakat baik lokal maupun luar negeri. Pemahaman teknologi pengolahan air sederhana sangat penting bagi masyarakat maupun instansi pemerintah dalam rangka antisipasi musim kemarau panjang dan menurunnya kualitas air baku dari tahun ke tahun.

\section{TEKNOLOGI PENGOLAHAN AIR DAN BUDAYA MASYARAKAT}

Pemilihan teknologi pengolahan air sangat terkait dengan kualitas sumber air dan kualitas air hasil olahan yang diinginkan. Semakin baik kualitas sumber air, maka biaya pengolahannya dengan kualitas hasil yang setara menjadi semakin murah. Dari aspek teknologi, proses pengolahan air tidak banyak mengalami perkembangan dalam dua puluh tahun terakhir.

Untuk aplikasi teknologi pengolahan air pada suatu wilayah, selain kondisi air baku, tergantung pula pada kondisi sosial ekonomi masyarakat, selain harga air olahan yang harus terjangkau oleh masyarakat. Dalam beberapa kondisi, masyarakat sering beranggapan air bersih harus didapat dengan gratis atau bebas. Di daerah yang sumber air langka atau kualitas airnya tidak memenuhi syarat, secara hukum ekonomi barang yang langka nilai ekonominya akan meningkat. Pada kondisi seperti ini, selain perlu intervensi pemerintah dalam bentuk bantuan fisik, perlu pula dalam jangka panjang dilakukan usaha-usaha pemberdayaan masyarakat, karena kekeringan mungkin tidak hanya datang satu kali, tetapi dapat terjadi setiap tahun.

Pada daerah yang langka sumber air tawarnya, ada dua kemungkinan solusinya. Jika sumber air tawar masih dapat dijangkau dalam jarak yang ekonomis, maka pengambilan air tawar dengan menggunakan mobil tangki atau perahu tongkang merupakan alternatif pilihan yang baik. Namun demikian untuk tempat-tempat yang cukup jauh dari sumber air dan harga air menjadi mahal, tidak ada pilihan lain, jika air asin atau air payaunya banyak, maka proses desalinasi menjadi alternatif pilihan. Teknologi yang umum dikenal masyarakat untuk mengolah air payau adalah teknologi reverse osmosis. Dalam aplikasi teknologi ini cocok untuk tempat yang tidak ada sumber air tawar dan pengelolaannya harus dikelola dengan managemen yang baik. Pengelolaan yang baik dapat dilihat di Desa Muncung, Tangerang, dengan kapasitas 20 m3/hari, Pulau Harapan, di Kepulauan Seribu dengan kapasitas 10 m3/hari, atau Pulau Saroppo Cakdi, di Pangkep, Sulawesi Selatan.

Dalam menerapkan teknologi pengolah air, partisipasi masyarakat menjadi penting, sebagai contoh, aplikasi teknologi TP2AS untuk mengolah air gambut di Pangkoh, Aluh-Aluh di Kalimantan dan Rawa Sragi di Lampung Timur. Secara teknologi, TP2AS sangat sederhana, pengoperasian mudah dan murah. Pada kesempatan pelatihan, masyarakat dapat mempraktekkan dalam waktu setengah hari latihan. Dalam waktu tiga puluh menit masyarakat sudah bisa mendapatkan 200 liter air bersih. Kenyataan yang dihadapi adalah tidak sampai satu tahun peralatan tersebut terbengkalai, walaupun ada beberapa yang masih bisa diperbaiki dan dipergunakan kembali.

Dari pandangan dan pengalaman tersebut, secara teknologi, pengolahan air tidak masalah bagi masyarakat. Namun demikian pemahaman pengoperasian belum sampai pada taraf merubah kebiasaan menjadi budaya hidup sehari-hari. Untuk merubah kebiasaan masyarakat mengolah air menjadi budaya sehari-hari membutuhkan waktu yang lebih lama dari pada sekedar pelatihan. Oleh karena itu dalam penerapan teknologi ini pemerintah perlu berdampingan dan bekerjasama dengan konsultan teknis dan lembaga swadaya 
masyarakat yang secara terus menerus memantau dan bergaul dengan masyarakat. Kegiatan ini banyak dilakukan oleh lembaga swadaya masyarakat dari luar negeri, yang saat ini bergerak di daerah pengungsian kerusuhan Sambas Kalimantan Barat.

\section{ALTERNATIF TEKNOLOGI PENGOLAHAN AIR BERSIH}

Dalam kaitannya dengan masalah air bersih di daerah pedesaan, beberapa jenis pengolahan air bersih yang berkaitan dengan masalah kekeruhan, kesadahan, air dengan organik tinggi (gambut), air yang mengandung zat besi dan mangan, dan air asin akan dijelaskan.

\subsection{Pengolahan Air Keruh}

Di daerah iklim tropis seperti Indonesia, pelapukan fisik sangatlah dominan, karena perbedaan temperatur siang dan malam yang cukup jauh mengakibatkan retak dan pecahnya batuan serta mudah terjadi erosi bila hujan datang. Hasil erosi yang terbawa air sungai ini mengakibatkan terjadinya kekeruhan sungai. Masalah ini banyak terjadi di setiap wilayah di Indonesia dan umumnya meningkat ketika musim hujan tiba.

Proses pengolahan air tergantung pada kekeruhan. Untuk air yang tidak terlalu keruh, pengolahan dapat dilakukan dengan proses penyaringan sederhana, yang dapat dilakukan individu maupun secara komunal. Jika kekeruhan cukup tinggi diperlukan unit penjernih atau Klarifier. Unit penjernih memerlukan bahan kimia. Setelah melalui tangki penjernih baru kemudian disaring dengan sistim saringan pasir lambat atau saringan pasir cepat, tergantung kebutuhan.

Proses pengolahan air keruh dengan penyaringan mempunyai keunggulan, murah didalam pemeliharaan dan perawatan, serta teknologinya cukup sederhana. Teknologi ini banyak dipakai dipedesaan, dengan kedala yang dihadapi berupa buntunya saringan pasir. Namun demikian dengan perkembangan baru sistem saringan dirubah dan proses pemeliharaan dapat menjadi lebih sederhana dan murah.

\section{Sistem Saringan Pasir Lambat Up Flow}

Teknologi Saringan Pasir Lambat (Sarpalam) yang banyak diterapkan di Indonesia biasanya adalah Sarpalam konvesional dengan arah aliran dari atas ke bawah (down flow), sehingga jika kekeruhan air baku naik, terutama pada waktu hujan, maka sering terjadi penyumbatan pada saringan pasir, sehingga perlu dilakukan pencucian secara manual dengan cara mengeruk media pasirnya dan dicuci, setelah bersih dipasang lagi seperti semula, sehingga memerlukan tenaga yang cukup banyak. Ditambah lagi dengan faktor iklim di Indonesia yakni ada musim hujan air baku yang ada mempunyai kekeruhan yang sangat tinggi. Hal inilah yang sering menyebabkan Sarpalam yang telah dibangun kurang berfungsi dengan baik, terutama pada musim hujan. Jika tingkat kekeruhan air bakunya cukup tinggi misalnya pada waktu musim hujan, maka agar supaya beban Sarpalam tidak telalu besar, maka perlu dilengkapi dengan peralatan pengolahan pendahuluan misalnya bak pengendapan awal atau saringan "Up Flow" dengan media berikil atau batu pecah, dan kwarsa atau silika. Selanjutnya dari bak saringan awal, air dialirkan ke bak saringan utama dengan arah aliran dari bawah ke atas (Up Flow). Air yang keluar dari bak saringan pasir Up Flow tersebut merupakan air olahan dan di alirkan ke bak penampung air bersih, selanjutnya didistribusikan ke konsumen dengan cara gravitasi atau dengan memakai pompa.

Diagram proses pengolahan bersih dengan sistem Sarpalam Up Flow ditunjukkan pada Gambar 1

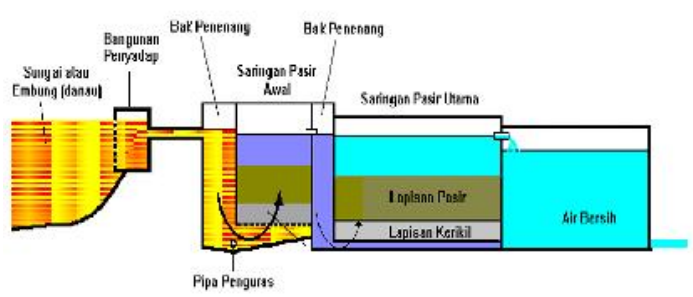

Gambar 1 : Diagram proses pengolahan bersih dengan sistem Sarpalam Up Flow.

Dengan sistem penyaringan dari arah bawah ke atas (Up Flow), jika saringan telah jenuh atau buntu, dapat dilakukan pencucian balik dengan cara membuka kran penguras. Dengan adanya pengurasan ini, air bersih yang berada di atas lapisan pasir dapat berfungsi sebagai air pencuci media penyaring (back wash). Dengan demikian pencucian media penyaring pada Sarpalam Up Flow tersebut dilakukan tanpa mengeluarkan atau mengeruk media penyaringnya, dan dapat dilakukan kapan saja.

Sarpalam "Up Flow" ini mempunyai keunggulan dalam hal pencucian media saringan (pasir) yang mudah, serta hasilnya sama dengan saringan pasir yang konvesional.

Kapasitas pengolahan dapat dirancang dengan berbagai macam ukuran sesuai dengan kebutuhan yang diperlukan. 


\section{Kriteria Perencanaan Sarpalam}

Untuk merancang Saringan Pasir Lambat (Sarpalam) beberapa kriteria perencanaan yang harus dipenuhi antara lain :

1. Kekeruhan air baku lebih kecil 10 NTU. Jika lebih besar dari 10 NTU perlu dilengkapi dengan bak pengendap dengan atau tanpa bahan kimia.

2. Kecepatan penyaringan $5-10 \mathrm{~m}^{3} / \mathrm{m}^{2}$.hari.

3. Tinggi lapisan pasir $70-100 \mathrm{~cm}$.

4. Tinggi lapisan kerikil $25-30 \mathrm{~cm}$.

5. Tinggi muka air di atas pasir $40-120 \mathrm{~cm}$.

6. Tinggi ruang bebas antara $25-40 \mathrm{~cm}$.

7. Diameter pasir kira-kira 0,2-0,4 mm

8. Jumlah bak penyaring minimal dua buah.

Salah satu contoh unit pengolahan air dengan Sarpalam "Up Flow" telah dibangun di Pesantren La Tansa, Lebak, Jawa barat, dengan kapasitas $100 \mathrm{M}^{3} /$ hari. Spesifikasi teknis unit saringangan pasir lambat up flow ditunjukkan seperti pada Tabel 1, sedangkan disain konstruksinya ditunjukkan seperti pada Gambar 2 sampai dengan Gambar 4. Foto unit Pengolahan air bersih dengan Sarpalam dengan arah aliran dari bawah ke atas (Up Flow) yang dibangun di Pesantren La tansa, Lebak, Jawa Barat dapat dilihat seperti pada Gambar 5.

Air baku yang digunakan adalah air dari saluran irigasi sekunder. Air sungai dialirkan secara garvitasi melalui banguan penyadap ke dalam bak penenang pertama, selanjutnya mengalir ke Bak saringan awal dengan arah aliran dari bawah ke atas (up flow) dengan kecepatan pengaliran $16 \mathrm{~m}^{3} / \mathrm{m}^{2}$.hari. Air hasil penyaringan dialirkan ke bak penenang ke dua dan selanjutnya masuk ke bak saringan pasir ke dua sistem aliran up flow dengan kecepatan penyaringan $5 \mathrm{~m}^{3} / \mathrm{m}^{2}$.hari. Air hasil penyanringan ke dua tersebut ditampung di dalam bak air bersih, selajutnya dialirkan ke kontaktor khlorine dan dilairkan ke konsumen.

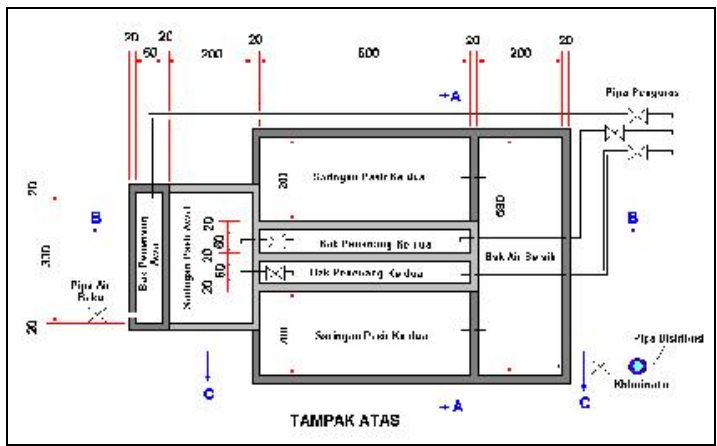

Gambar 2 : Rancangan alat pengolah air bersih" Sarpalam Up Flow" kapasitas 100 M3/hari. Tampak Atas.
Tabel 1 : Spesifikasi Teknis Pilot Plant Sarpalam Up Flow Kapasitas 100 m³/hari.

\begin{tabular}{|c|c|}
\hline $\begin{array}{l}\text { Kapasitas } \\
\text { Pengolahan }\end{array}$ & $100 \mathrm{~m}^{3} /$ Hari. \\
\hline $\begin{array}{l}\text { Bangunan } \\
\text { Penyadap }\end{array}$ & Pipa PVC dia. 4 " (berlubang) \\
\hline $\begin{array}{l}\text { Bak } \\
\text { Penerima / } \\
\text { Bak } \\
\text { Penenang } \\
\text { Awal }\end{array}$ & $80 \mathrm{~cm} \times 300 \mathrm{~cm} \times 250 \mathrm{~cm}$ \\
\hline \multicolumn{2}{|l|}{$\begin{array}{l}\text { Saringan Up } \\
\text { Flow Awal }\end{array}$} \\
\hline Ukuran : & $200 \mathrm{~cm} \times 300 \mathrm{~cm} \mathrm{X} 225 \mathrm{~cm}$ \\
\hline $\begin{array}{l}\text { Tebal } \\
\text { Lapisan } \\
\text { Kerikil : }\end{array}$ & $\begin{array}{l}\text { Batu Pecah, ukuran2-3 } \mathrm{cm}: 20 \mathrm{~cm} \\
\text { Batu Pecah , ukuran } 1-2 \mathrm{~cm}: 10 \mathrm{~cm} \\
\text { Pasir : } 70 \mathrm{~cm} \\
\text { Kecepatan Penyaringan }: 16 \mathrm{~m}^{3} / \mathrm{m}^{2} . \text { Hari. }\end{array}$ \\
\hline $\begin{array}{l}\text { Bak } \\
\text { Penenang } \\
\text { Ke Dua }\end{array}$ & $80 \mathrm{~cm} \mathrm{X} 500 \mathrm{~cm} \times 225 \mathrm{~cm}$ (2 Buah) \\
\hline \multicolumn{2}{|l|}{$\begin{array}{l}\text { Saringan } \\
\text { Pasir Up } \\
\text { Flow Kedua }\end{array}$} \\
\hline Ukuran : & $\begin{array}{l}200 \mathrm{~cm} \times 500 \mathrm{~cm} \times 200 \mathrm{~cm} \\
\text { (2 buah) }\end{array}$ \\
\hline $\begin{array}{l}\text { Tebal } \\
\text { Lapisan } \\
\text { Kerikil : }\end{array}$ & $\begin{array}{l}\text { Batu Pecah, ukuran } 2-3 \mathrm{~cm}: 20 \mathrm{~cm} \\
\text { Batu Pecah, ukuran } 1-2 \mathrm{~cm}: 10 \mathrm{~cm} \\
\text { Pasir : } 70 \mathrm{~cm} \\
\text { Kecepatan Penyaringan } 5 \mathrm{~m}^{3} / \mathrm{m}^{2} \text {.hari. }\end{array}$ \\
\hline $\begin{array}{l}\text { Bak Air } \\
\text { Bersih }\end{array}$ & $200 \mathrm{~cm} \mathrm{X} 580 \mathrm{~cm} \mathrm{X} 200 \mathrm{~cm}\left( \pm 20 \mathrm{M}^{3}\right)$ \\
\hline $\begin{array}{l}\text { Bahan } \\
\text { bangunan }\end{array}$ & Beton semen cor \\
\hline
\end{tabular}

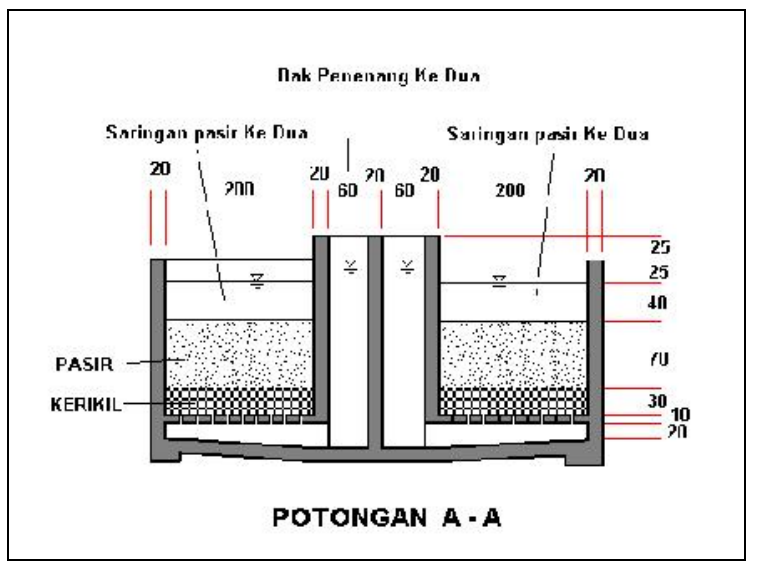

Gambar 3 : Rancangan alat pengolah air bersih " Sarpalam Up Flow" kapasitas 100 M3/hari. Potongan A - A. 


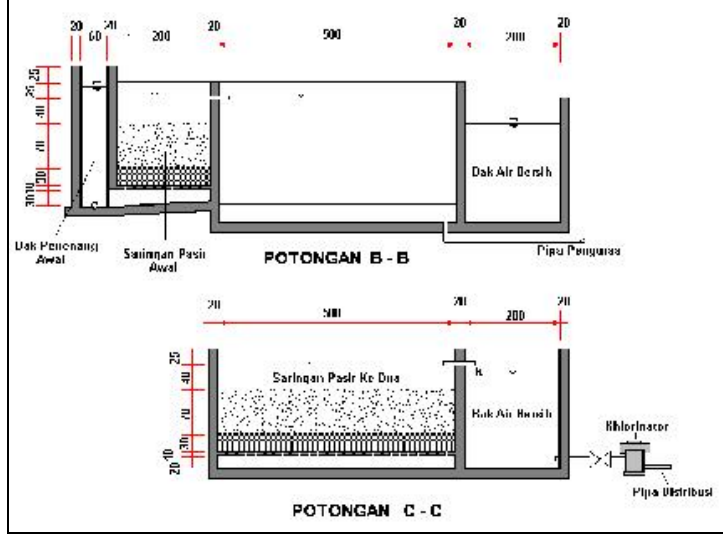

Gambar 14 : Rancangan "Sarpalam Up Flow" kapasitas 100 M3/hari. Potongan B-B dan C-C.

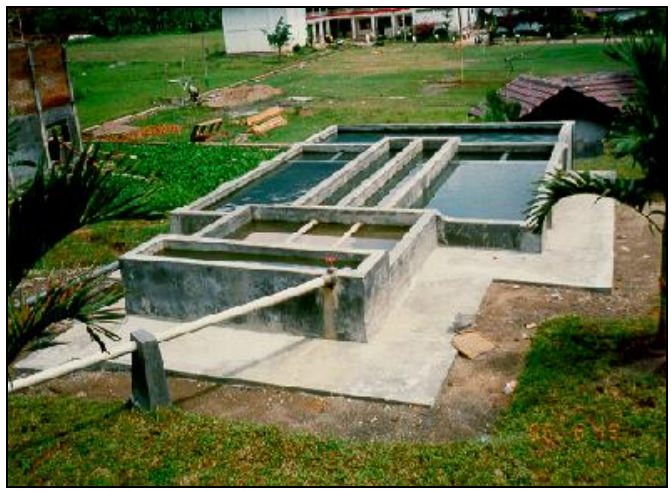

Gambar 5 : Unit Pengolahan Air Bersih Sarpalam dengan sistem arah aliran dari bawah ke atas (Up Flow) kapasitas $100 \mathrm{M}^{3} /$ hari. Lokasi : Pesantren Latansa, Lebak, Jawa Barat.

Keunggulan Sarpalam upflow adalah proses pengolahan yang sedehana, proses penyaringan secara up flow, sehingga tidak mudah buntu, mudah dalam pembersihan, dan perawatan. Kendala dalam pengoperasian adalah unit ini hanya bisa untuk mengolah air dengan kekeruhan rendah, jika kekeruhannya tinggi memerlukan bantuan tangki penjernih sebelum air masuk kedalam sarpalam.

\subsection{Pengolahan Air Sadah}

Air sadah atau air yang banyak mengandung kapur tinggi, banyak dijumpai di daerah yang berbatuan kapur, seperti di Gunung Kidul, Malang Selatan, Sulawesi Tengah dan Tenggara. Untuk mengolah air sadah biasanya masyarakat melakukan pemanasan, agar garam sadahnya dapat mengendap dalam bentuk kerak di bagian bawahnya. Untuk kuantitas yang lebih besar seperti keperluan mandi atau mencuci, pemanasan masih dianggap mahal, oleh karena perlu alternatif lain yang lebih murah. Salah satu alternatifnya adalah penggunaan resin. Teknik yang digunakan sama seperti proses filtrasi, yaitu dengan menggunakan tabung yang berisi media resin. Hanya saja dalam proses ini, yang terjadi adalah proses pertukaran ion. Proses pengurangan kesadahan sangat efektif dan secara berkala perlu dilakukan regenerasi resin dengan menggunakan garam dapur.

Keunggulan pengolah air sadah tipe ini adalah praktis dalam pengolahan dan pencuciannya, kualitas air olahannya baik dan dapat memenuhi syarat kesehatan. Kendala penerapan dilapangan, terutama di daerah yang tidak ada listrik, perlu pembuatan tower, minimal tiga meter, perlu pemompaan untuk menaikkan air. Tetapi jika ada listrik, penggunakan alat ini cukup ditambah pompa untuk memberikan tekanan pada saat proses filtrasi.

Unit ini mudah pemasangannya dan murah biaya pemeliharaannya. Pada daerahdaerah yang kapurnya tinggi, sedikit banyak mempengaruhi kebiasaan masyarakat dalam meminum air. Keberhasilan dalam penerapan teknologi ini perlu didukung oleh langkah sosialisasi yang panjang, karena kualitas yang baik belum tentu cocok buat lidah masyarakat yang terbiasa meminum dengan sumber daya yang ada.

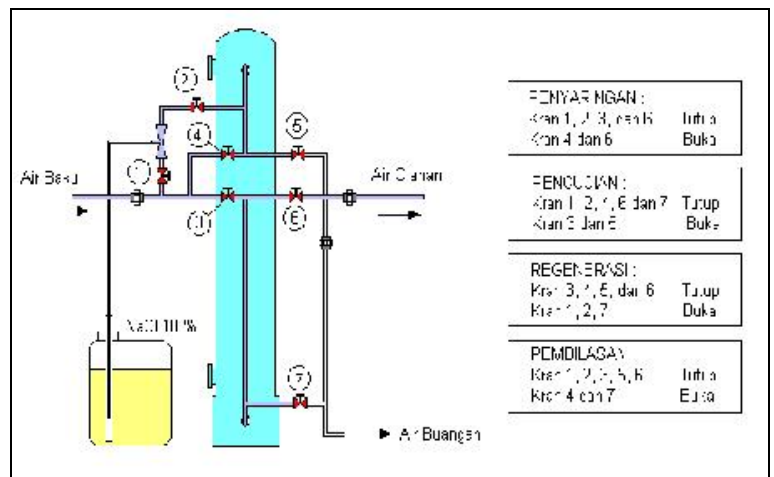

Gambar 6 : Diagram proses penghilangan kesadahan dengan proses pertukaran ion.

\subsection{Pengolahan Air Gambut}

Air gambut merupakan air permukaan dari tanah bergambut dengan ciri yang sangat mencolok karena warnanya merah kecoklatan, mengandung zat organik tinggi, rasa asam, $\mathrm{pH}$ 2-5 dan tingkat kesadahan rendah. Proses pengolahan terdiri dari beberapa tahapan, yaitu : 1). Netralisasi, untuk menaikkan pH larutan 2). Oksidasi, untuk mengoksidasi zat organik dan logam terlarut 3). Koagulasi, untuk menggumpalkan zat organik dan logam yang teroksidasi 4). Pengendapan, untuk mengendapkan zat yang terkoagulasi 5). Penyaringan dan 6). Desinfeksi (Gambar 3). 


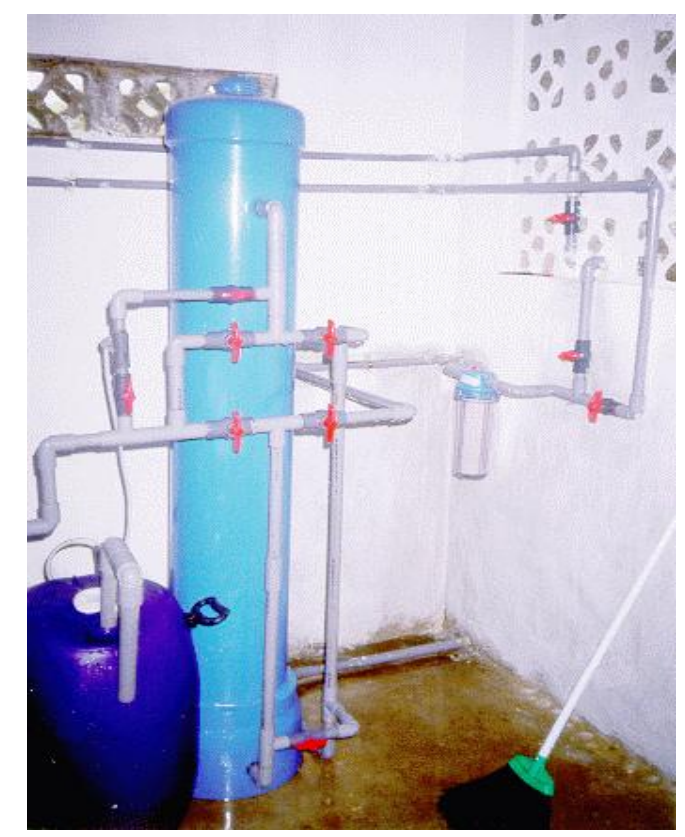

Gamabar 7 : Unit peralatan penghilangan kesadahan dengan proses pertukaran ion.

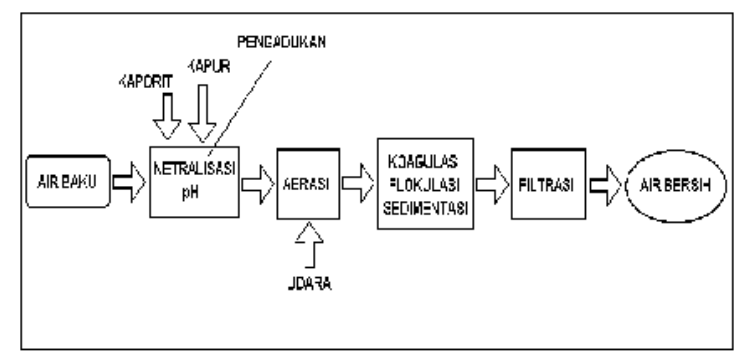

Gambar 8 : Diagram proses pengolahan air gambut.

\subsubsection{Pengolahan Air Gambut Individual}

Untuk aplikasi sederhana Teknologi TP2AS (Tong, Pengaduk, Pengendap, Aerasi, dan Saringan) yang sudah diperkenalkan kemasyarakat sejak tahun 1985 ini, cukup handal. Dalam waktu 60 menit, masyarakat sudah bisa mendapatkan 400 - 450 liter air bersih. Kendala pengoperasian di lapangan yang dihadapi adalah masyarakat enggan untuk menimba air ke dalam bak, sulitnya memperoleh tawas di daerah, atau mereka enggan atau berat untuk mengeluarkan uang lebih untuk mengolah air. Untuk masalah pengangkutan air dapat di atasi dengan cara memasang pompa tangan seperti dragon, dengan merendahkan tinggi bak penampung dan memperpanjang pipa hisap pompanya, dengan demikian masyarakat tidak perlu menimba air lagi. Tawas sebagai koagulan, sekarang banyak dijual bebas, dan sudah banyak dipasar-pasar, dengan harga yang tidak terlalu mahal.
Dengan teknologi sederhana air olahan yang dihasilkan cukup bagus (Gambar 9 dan Gambar 10), masyarakat dengan mudah secara visual mendapat air bersih dalam waktu singkat. Biaya proses cukup murah untuk di daerah yang langka air bersih, dengan kualitas yang cukup memadai (Tabel 2).

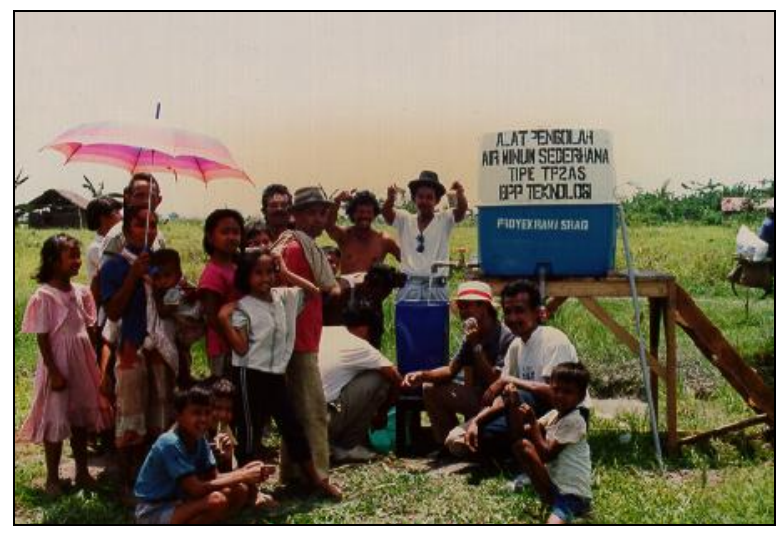

Gambar 9: Percontohan Alat Pengolah Air Minum Sederhana di Daerah Rawa Sragi, Lampung.

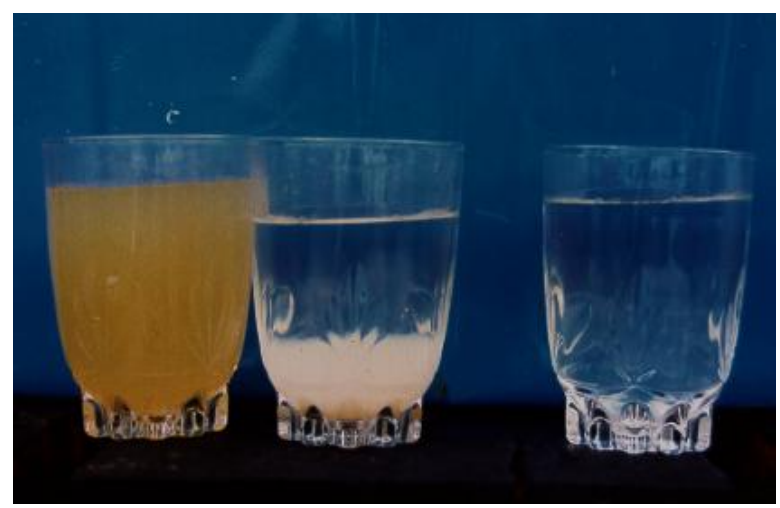

Gambar 10 : Air baku, air olahan yang belum disaring, dan air olahan setelah disaring.

\subsubsection{Unit Pengolahan Air Gambut Komunal}

Untuk keperluan pengolahan kontinyu, atau secara massal dapat dilakukan pada tempat yang pemukimannya terkumpul, dan dikelola oleh pengelola yang merupakan wakil warga. Kapasitasnya dapat berkisar 60 - 100 m3/hari. Investasi peralatan ini cukup besar dan harus ada peran pemerintah untuk membantu masyarakat pedesaan. Aplikasi teknologi ini baik dalam rangka membuat cadangan air bersih dalam cukup besar di daerah gambut, dalam rangka persiapan menghadapi musim kering atau kemarau panjang. 
Tabel 2. Hasil analisa kualitas air baku dan air olahan

\begin{tabular}{|c|c|c|c|c|c|c|}
\hline \multirow[b]{2}{*}{$\begin{array}{l}N \\
0\end{array}$} & \multirow[b]{2}{*}{ Parameter } & \multirow[b]{2}{*}{$\begin{array}{l}\text { Satu } \\
\text { an }\end{array}$} & \multicolumn{2}{|c|}{ Contoh Air (1) } & \multicolumn{2}{|c|}{ Contoh Air (2) } \\
\hline & & & baku & olahan & baku & olahan \\
\hline 1 & $\mathrm{pH}$ & - & 3,8 & 6,8 & 7,6 & 7,65 \\
\hline 2 & Kekeruhan & NTU & 10 & 1,5 & 28 & 2 \\
\hline 3 & Warna & $\begin{array}{l}\text { Pt- } \\
\text { Co }\end{array}$ & 500 & 10 & 18 & 6 \\
\hline 4 & Besi (Fe) & $\mathrm{mg} / \mathrm{tt}$ & 0,4 & 0,18 & 17,39 & 0,26 \\
\hline 5 & $\begin{array}{l}\text { Mangan } \\
\text { (Mn) }\end{array}$ & $\mathrm{mg} / \mathrm{tt}$ & 0 & $\mathrm{ttd}$ & 0,04 & $\mathrm{ttd}$ \\
\hline 6 & Organik & $\mathrm{mg} / \mathrm{tt}$ & 470 & 10,5 & 1,77 & 2,88 \\
\hline 7 & $\begin{array}{l}\text { Zat padat } \\
\text { terlarut }\end{array}$ & $\mathrm{mg} / \mathrm{lt}$ & 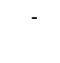 & 253 & 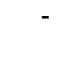 & 144 \\
\hline
\end{tabular}

Keterangan :

1. Air gambut di daerah Pangkoh, Kalimantan Tengah.

2. Air Tanah di Kecamatan Benama Tingang, Kalimantan Tengah.

Pada daerah yang luas, pemasangan jaringan perpipaan akan memakan biaya yang mahal, oleh karena itu sebaiknya kualitas air olahannya ditingkatkan agar dapat dibotolkan dan dikirim ke daerah yang cukup jauh dengan tetap menjaga kualitas tetap baik. Di daerah pedalaman air kemasan cukup mahal, tetapi masyarakat tetap membeli, karena mereka butuh dan sudah merasakan manfaatnya. Pemerintah perlu membentuk unit usaha untuk meningkatkan kemandirian masyarakat di daerah pedesaan, dengan demikian tidak terjadi kepanikan ketika musim kemarau tiba, karena masyarakat sudah dapat mengatasi masalah mereka sendiri, mungkin yang masih diperlukan adalah bantuan biaya operasional.

Salah satu contoh pilot plant ini dibangun di daerah pemukiman transmigrasi di Kabupaten Kuala Kapuas, Kalimantan Tengah dengan kapasitas $30 \mathrm{M}^{3}$ per hari. Air yang akan diolah adalah air sungai dengan kandungan zat besi yang cukup tinggi yakni mencapai $10 \mathrm{mg} / \mathrm{l}$ dengan $\mathrm{pH}$ yang rendah yakni sekitar $\mathrm{pH} 4$. Secara fisik air berwarna coklat dan berbau logam.

Proses yang digunakan yakni kombinasi proses pengaturan $\mathrm{pH}$, proses koagulasi flokulasi dengan menggunakan larutan tawas atau PAC, serta pembubuhan kalium permanganat dan dilanjutkan dengan proses filtrasi. Proses penyaringan terdiri dari tiga tahap yakni penyaringan dengan saringan pasir, kemudian penyaringan dengan filter mangan zeolit (manganese greensand) dan selanjutnya penyaringan dengan media karbon aktif. Diagram proses pengolahannya dapat dilihat seperti pada Gambar 11.

Air baku yang berasal dari air air tanah dipompa ke tangki pencampur (static mixer) sambil diinjeksi dengan larutan soda ash $\left(\mathrm{NaHCO}_{3}\right)$ atau larutan kapur untuk menaikkan
pH menjadi sekitar $\mathrm{pH}$ 7-8, dan diinjeksi dengan larutan tawas selanjutnya dialirkan ke bak clarifier atau bak pengendap. $\mathrm{Di}$ dalam bak pengendap, dengan adanya penambahan soda ash dan larutan tawas, zat besi atau mangan akan dengan cepat teroksidasi menjadi oksida besi atau oksida mangan yang tidak larut di dalam air dan akan mengendap di dalam bak pengendap.

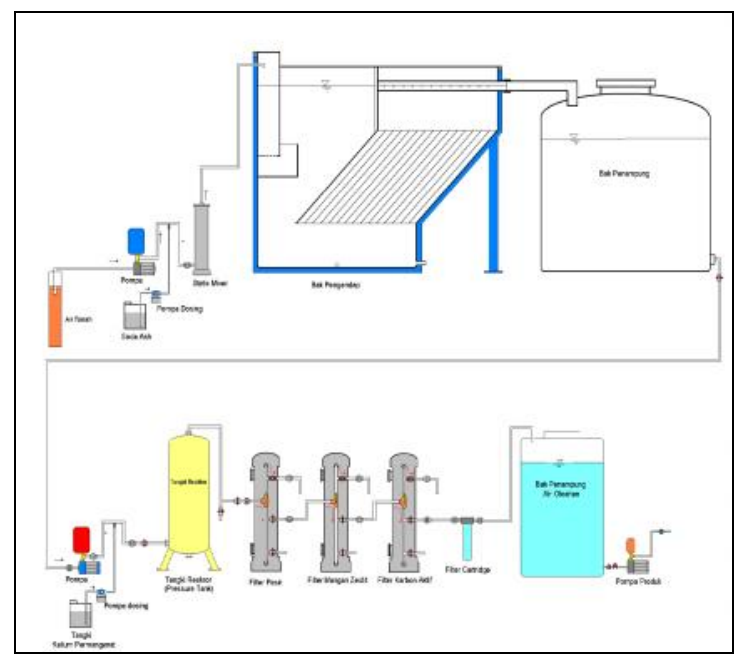

Gambar 11 : Diagram proses penghilangan zat besi dan mangan di dalam air.

Air limpasan dari bak pengendap selanjutnya dialirkan ke bak penampung air baku. Dari bak penampung air baku, air dipompa ke tangki reaktor (tangki bertekanan) sambil diinjeksi dengan larutan kalium permanganat dengan menggunakan pompa dosing, agar zat besi atau mangan yang belum teroksidasi di dalam bak pengendap dapat dioksidasi lebih sempurna menjadi bentuk senyawa oksida besi atau mangan yang tak larut dalam air.

Zat besi atau mangan di dalam air yang telah teroksidasi dan juga padatan tersuspensi yang berupa partikel halus, selanjutnya di alirkan ke filter pasir (sand filter). Air yang keluar dari saringan pasir selanjutnya dialirkan ke filter mangan zeolit (manganese greensand filter). Dengan adanya filter mangan zeolit ini, zat besi atau mangan yang belum teroksidasi di dalam tangki reaktor dapat dihilangkan sampai konsentrasi $<0,1 \mathrm{mg} / \mathrm{l}$.

Kombinasi proses pengaturan $\mathrm{pH}$, proses koagulasi-flokulasi dengan larutan tawas, pembubuhan kalium permanganat dan dilanjutkan dengan proses filtrasi

Dari filter Mangan Zeolit, air dialirkan ke filter karbon aktif (activated carbon filter) untuk menghilangkan bau atau warna serta polutan mikro. Filter ini mempunyai fungsi untuk menghilangkan senyawa warna dalam air, serta untuk menghilangkan senyawa yang dapat 
menyebabkan bau. Setelah melalui filter penghilangan warna, air dialirkan ke filter cartridge yang dapat menyaring partikel kotoran sampai ukuran 5 mikron. Dari filter cartridge, selanjutnya, air dialirkan ke bak penampung air olahan dan selanjutnya dipompa ke saluran distribusi. Konstruksi peralatan yang telah terpasang dapat dilihat pada Gambar 12.

\subsection{Pengolahan Air Asin atau Payau}

Masalah air yang sulit dihadapi masyarakat adalah ketika menghadapi kenyataan air di daerahnya pada musim kemarau berubah menjadi asin atau payau. Ada dua teknologi yang umum digunakan untuk mengolah air asin, pertama teknologi destilasi, yang umum dipakai dalam skala besar atau pada tempat-tempat atau industri yang mempunyai panas buang yang tinggi, kedua teknologi reverse osmosis yang menggunakan membran dan tekanan dalam proses pengolahannya.

Aplikasi teknologi desalinasi harus mempertimbangkan kondisi sosial ekonomi masyarakat pedesaan. Untuk pengoperasian unit desalinasi membutuhkan biaya operasional dan pemeliharaan. Sebaiknya tidak diterapkan pada daerah yang dekat dengan sumber air tawar atau secara ekonomis masih memungkinkan. Penerapan teknologi ini kompetitif untuk daerah yang langka air tawar, ditepi pantai atau pulau yang tidak ada sumber air tawar ketika musim kemarau, tetapi secara ekonomi masyarakatnya mampu. Jika dibandingkan dengan air bersih biaya operasional unit desalinasi masih relatif mahal, tetapi jika dibandingkan dengan air minum dalam kemasan harga tersebut sangat murah.

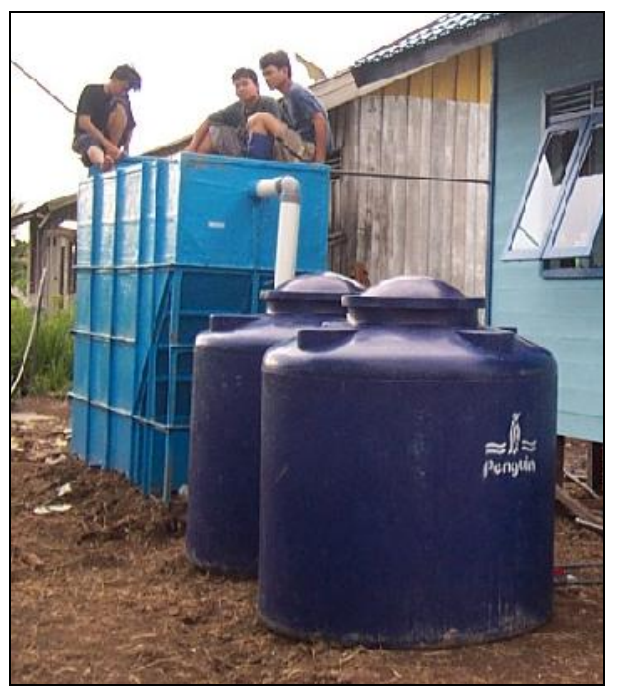

Gambar 12 : Bak pengendap yang berfungsi juga sebagai kontaktor udara kontaktor udara dan bak penampung.
Teknologi reverse osmosis sudah banyak diterapkan diberbagai tempat di Indonesia, antara lain di P. Tidung, Pramuka, Kelapa, Harapan, Panjang, Untung Jawa (di Kepulauan Seribu), Sungai Lumpur dan Air Sugihan (Kalimantan Selatan), Tembilahan (Riau), Sei Rasau (Kalsel), Raha Pulau Muna (Sultra), Muncung (Tangerang), Muara Gembong (Bekasi), Pulau Saroppo Cakdi (Sulsel) dan masih banyak lagi. Keberhasilan dalam pengelolaan umumnya berkat adanya pengelola yang baik dan kooperatif. Di beberapa tempat dipasang, hanya sebagai unit emergensi ketika musim kemarau tiba. Kegagalan dalam aplikasi teknologi reverse osmosis juga akibat, masalah sosial seperti kehilangan pompa, diesel pembangkit listrik, atau tidak mampu memasarkan produk airnya dan mengelola dana yang terkumpul.

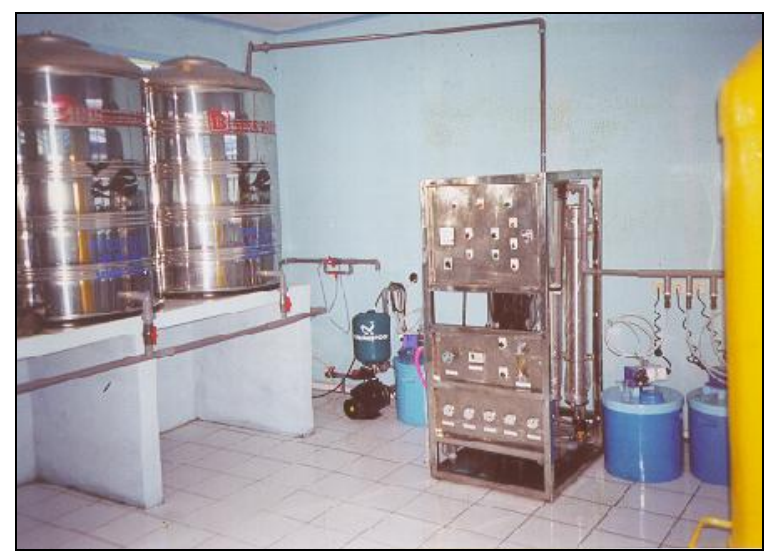

Gambar 13: Pengolahan Air Sistem Reverse Osmosis $20 \mathrm{~m}^{3} /$ hari.

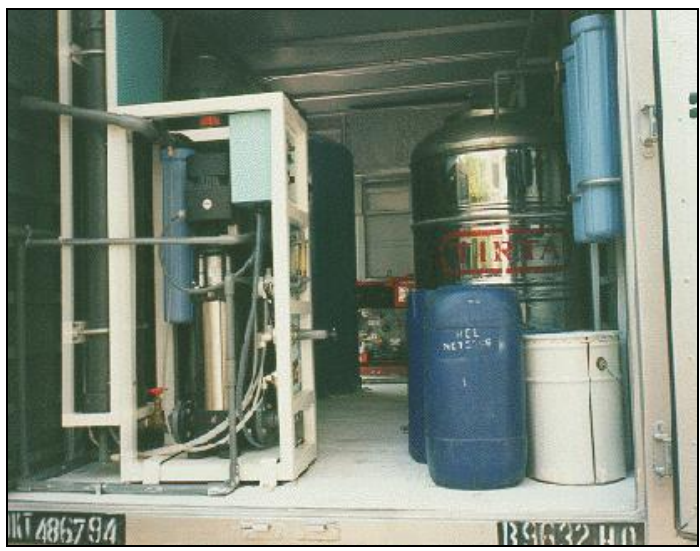

Gambar 14 : Pengolahan Air Sistem Reverse Osmosis Mobile Unit 10 m3/hari.

\subsection{Teknologi Ultrafiltrasi dan Biofiltrasi}

Sejalan dengan peningkatan pencemaran pada sumber-sumber air baku dan terbatasnya kemampuan teknologi konvensional, maka pada 
masa yang akan datang, sejalan dengan perkembangan ekonomi, diperlukan teknologi lanjutan sebagai jaminan terhadap kesempurnaan proses pengolahan air minum.

Teknologi biofiltrasi diperlukan sebagai langkah antisipasi untuk mengurangi pencemaran limbah domestik organik pada perairan. Air baku yang banyak mengandung bahan organik akan menyerap pemakaian kaporit yang lebih tinggi untuk proses pemurnian air, sementara bersamaan dengan itu kadar Trihalomethan dalam air olahan juga meningkat. Oleh karena itu pemakaian teknologi biofiltrasi pada masa yang akan datang diperlukan sebagai unit pretreatment, terutama pada kotakota besar yang sumber air bakunya mengandung bahan organik yang cukup tinggi. Proses biofiltrasi ini sangat diperlukan karena proses filtrasi pada teknologi konvensional hanya mengurangi padatan yang tersuspensi dan tidak mampu mengurangi padatan yang terlarut.

Teknologi Ultrafiltrasi merupakan teknologi tambahan dalam pengolahan air bersih, terutama ditujukan untuk pengolahan air siap minum. Ukuran partikel yang mampu disaring sampai dengan 0,02 mikron, dengan demikian diharapkan bakteri dan polutan mikro dapat tersaring. Teknologi ini hanya dapat dipakai untuk air tawar dan tidak bisa untuk air asin. Saat ini teknologi ultrafiltrasi mulai banyak dipakai di kota-kota besar dunia (Gambar 15).

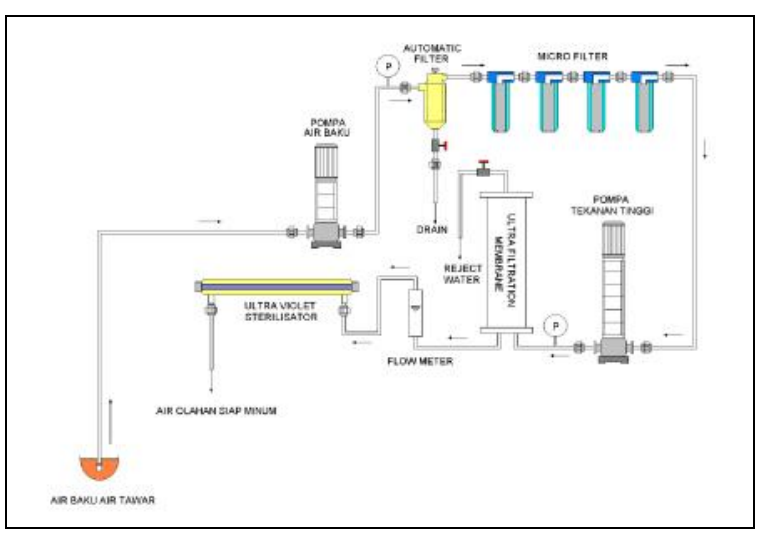

Gambar 15 : Proses pengolahan air minum dengan sistem ultra filtrasi.

\section{PENUTUP}

Berdasarkan pengalaman, secara teknologi, pengolahan air bersih di daerah pedesaan haruslah mudah dan murah biaya operasionalnya. Mudah dalam arti untuk mengolah air dalam jumlah yang dibutuhkan tidak memerlukan waktu yang lama dan tenaga yang besar, sedangkan pengertian murah adalah tidak membutuhkan biaya yang besar untuk mengolah air baku menjadi air bersih. Untuk itu unit-unit yang sudah ada dan pernah diaplikasikan di daerah pedesaan, perlu untuk dilakukan modifikasi dan evaluasi agar menjadi lebih mudah, dan untuk mendukung keberlanjutannya perlu dilakukan survei bahan dan evaluasi untuk menghitung biaya operasionalnya.

Biasanya pada saat pelatihan operasional unit-unit pengolah air dilakukan hanya dalam waktu yang sangat singkat, sehingga mereka baru sampai pada tahap mengerti akan apa yang dijelaskan, tetapi belum sampai pada perubahan budaya dan prilaku untuk membiasakan diri untuk meminum air yang sudah diolah. Dalam perberdayaan masyarakat perlu melibatkan lembaga swadaya masyarakat setempat agar pembinaan dapat lebih intensif dan terus menerus, sehingga suatu saat masyarakat dapat mandiri dalam pengadaan air bersih.

Dalam rangka menghadapi musim kemarau panjang, dimana banyak daerah pedesaan yang kesulitan air, maka pemerintah dan lembaga-lembaga yang berkaitan dengan pemberdayaan masyarakat, perlu mengambil langkah antisipasi untuk meringankan beban masyarakat pedesaan dengan memberi solusi yang nyata, baik dalam jangka pendek maupun panjang.

Permasalahan yang sering muncul dilapangan adalah masalah biaya opersional unit-unit pengolah air bersih. Oleh karena itu pembangunan unit pemgolah air harus disertai pembinaan managemennya. Air merupakan kebutuhan pokok masyarakat, pasarnya sudah ada, oleh karena itu air ada harganya. Namun demikian penetapan harga air olahan harus juga mempertimbangkan air sebagai fungsi sosialnya.

\section{DAFTAR PUSTAKA}

1. Arie. $\mathrm{H}, 1988$, Sistem Penyediaan Air Bersih di Propinsi Timor Timor, Direktorat Pengkajian Sistemn, Kedeputian Analisis Sistem, BPPT, Jakarta.

2. Arie. H, 2000, Aplikasi Teknologi Reverse Osmosis Kapasitas $20 \mathrm{~m}^{3} / \mathrm{hari}$ di Desa Muncung, Tangerang, BPPT, Jakarta.

3. Arie. H, 2001, Aplikasi Teknologi Sarpalam 100 UF di Desa Padang Cermin, Lampung, Journal Teknologi Lingkungan, Vol 2 No 2, P3TL, BPPT, Jakarta.

4. Arie. H, Dharmawan dan Komariah, 1988, Uji Coba Teknologi Reverse Osmosis Sistem X Flow RO - 01, Direktorat Pengkajian Sistem, Deputi Bidang Analisis Sistem, BPPT, Jakarta.

5. Arie, H, Nusa. I..S, Nugro. R, dan Haryoto, I., 1996, Studi Penerapan Teknologi Pengolahan Air Payau Kapasitas 10 m3/hari, 
Direktorat Pengkajian Sistem Industri Jasa, Deputi Bidang Analisis Sistem, BPPT, Jakarta.

6. Brault. J.B., 1991, Water Treatment Handbook, Vol 1 dan 2, $6^{\text {th }}$ Edition, Degremont, Lavoisier Publishing, Cedex, France.

7. JWWA, 1978, Design Criteria For Waterworks Facilities, , $4^{\text {th }}$ Edition, Japan Water Works Association, Kogusuri Printing Co., Ltd. , Tokyo.

8. Kompas, Rabu, 11 Juni 2003, Lahan Tak Bisa Diolah, Ribuan Transmigran Telantar, Banyuasin

9. Kompas, Senin, 15 September 2003, Air Tanah di DKI Jakarta Tercemar Bakteri E. coli.

10. Nusa. I.S, 1994, Aplikasi Teknologi Saringan Pasir Lambat di Pesantren Latanza, Lebak, Kerjasama BPPT dengan PII.

11. Nusa, I.S., Arie, H., Nugro, R., dan Haryoto, I., 1996, Studi Kelayakan Teknis dan Ekonomis Unit Pengolah Air Sistem Reverse Osmosis Kapasitas 500 m3/hari Untuk perusahaan minyak lepas pantai, P.T. Paramita Binasarana, Jakarta.

12. Middleton. R, 2003, Air Bersih Sumber Daya Yang Rawan, American Water Works Association, West Quincy Avenue, Denver, Colo. 80235 U.S.A.

13. Ruliasih. M dan Arie. H, 1994, Sistem Pengambilan Keputusan Penentuan Metode Pengelolaan Air, Journal Analisis Sistem, No. 1, Tahun 1, Kedeputian Bidang Analisis Sistem, BPPT, Jakarta.

14. Sasakura, 1995, Desalination Technology and Its Aplication, P.T. Sasakura Indonesia, Jakarta. 